\title{
Oculocutaneous albinism in a patient with 17p13.2-pter duplication - a review on the molecular syndromology of $17 \mathrm{p} 13$ duplication
}

\author{
Marzena Kucharczyk ${ }^{\mathrm{a}}$, Aleksandra Jezela-Stanekª, Dorota Gieruszczak-Bialek ${ }^{\mathrm{a}, \mathrm{b}}$, Monika Kugaudo o, , Agata Cieslikowska ${ }^{\mathrm{a}}$, \\ Magdalena Pelc ${ }^{\mathrm{a}}$, Malgorzata Krajewska-Walasek ${ }^{\mathrm{a}}$
}

Background. Chromosomal duplications involving 17p13.3 have recently been defined as a new distinctive syndrome with several diagnosed patients. Some variation is known to occur in the breakpoints of the duplicated region and, consequently, in the phenotype as well.

Aims. We report on a patient, the fifth to our knowledge, a 4-year-old girl with a pure de novo subtelomeric 17p13.2pter duplication. She presents all of the facial features described so far for this duplication and in addition, a unilateral palmar transversal crease and oculocutaneous albinism which has not been reported previously.

Methods. A detailed molecular description of the reported aberration and correlation with the observed phenotypical features based on a literature review. We discuss the possible molecular etiology of albinism in regard to the mode of inheritance.

Conclusion. The new data provided here may be useful for further genotype correlations in syndromes with oculocutaneous albinism, especially of autosomal dominant inheritance.

Key words: chromosomal duplication, 17p13.3, albinism

Received: September 22, 2014; Accepted with revision: January 15, 2015; Available online: February 10, 2015 http://dx.doi.org/10.5507/bp.2015.003

${ }^{a}$ Department of Medical Genetics, Children's Memorial Health Institute, Warsaw, Poland
${ }^{b}$ Department of Pediatrics, Medical University of Warsaw, Warsaw, Poland
'Department of Child and Adolescent Psychiatry, Medical University of Warsaw, Warsaw, Poland
Corresponding author: Aleksandra Jezela-Stanek, e-mail: jezela@gmail.com

\section{INTRODUCTION}

Chromosomal duplications involving 17 p 13.3 have recently been defined as a new distinctive syndrome (MIM\#613215) with more than 40 diagnosed patients ${ }^{1-7}$. This disorder represents a contiguous gene duplication syndrome involving the genes PAFAH1B1 (LIS1) and/or $Y W H A E$. The same region on chromosome $17 \mathrm{p} 13.3$ is deleted in Miller-Dieker lissencephaly syndrome (MDLS).

The phenotypic features of 17 p 13.3 duplication may include: intrauterine growth retardation (IUGR), mild to moderate psychomotor delay, hypotonia, and craniofacial dysmorphism such as: high forehead with frontal bossing, small nose and mouth, subtle hand/foot malformations. Nevertheless, the phenotype varies depending on the breakpoints of the duplicated region and, consequently, on the gene content. Bruno et al. suggested that there are 2 classes of microduplications of 17p13.3. Class I involves $Y W H A E$, but not $P A F A H 1 B 1$, whereas class II duplications involve $P A F A H 1 B 1$ and may also include $C R K$ and $Y W H A E$ (ref. ${ }^{4}$ ).

Here, we report on another patient, a 4-year-old girl, with a pure de novo subtelomeric class II duplication of 17p13.2-pter identified by MLPA (Fig. 1). This finding was confirmed and further characterized by FISH and array CGH studies (Fig. 2, 3, respectively). It was found that a $5.77 \mathrm{Mb}$ duplicated region of 17p13.2-pter resided on the non-deleted terminal region of chromosome $14 \mathrm{p}$.

\section{CLINICAL SUMMARY}

The girl is the second child of healthy nonconsanguineous parents, aged 27 years. She was born by vaginal delivery in the $39^{\text {th }}$ week of gestation after an uneventful pregnancy. Her birth weight was $2680 \mathrm{~g}\left(5^{\text {th }}-10^{\text {th }}\right.$ centile $)$, birth length, $55 \mathrm{~cm}$, and head circumference, $32 \mathrm{~cm}$. Her Apgar score was 10 points. Clinical examination of the newborn showed capillary haemangioma on the eyelids, forehead and nape, which disappeared by the time of genetic evaluation.

The girl's development was delayed: she began to sit at 12 months and walk at 24 months; her gait at 4 years was unstable. At the age of 2 years she spoke a few words but then stopped speaking. Her anthropometric results at 1 year 5 months were: height $77.7 \mathrm{~cm}\left(25^{\text {th }}-50^{\text {th }}\right.$ centile), weight $9 \mathrm{~kg}\left(25^{\text {th }}-50^{\text {th }}\right.$ centile $)$, OFC (occipital frontal circumference) $44 \mathrm{~cm}$ ( $3^{\text {rd }}-10^{\text {th }}$ centile $)$, and then at 5 years, during follow-up at our genetic department: height 108 $\mathrm{cm}\left(25^{\text {th }}-50^{\text {th }}\right.$ centile $)$, weight $18.5 \mathrm{~kg}\left(25^{\text {th }}-50^{\text {th }}\right.$ centile $)$, and OFC $49 \mathrm{~cm}$ ( $3^{\text {rd }}-10^{\text {th }}$ centile $)$.

At the age of 7 months she developed epilepsy. Echocardiography and ultrasonography of the brain and abdomen were normal. Investigation for biotinidase deficiency and organic acidurias revealed no abnormalities, and plasma amino acids were normal. Ophtalmological examination showed myopia: (R: - 3.5 Dsf, L: - 2.25 Dsf), and nystagmus. Moreover, lack of retinal pigment with 


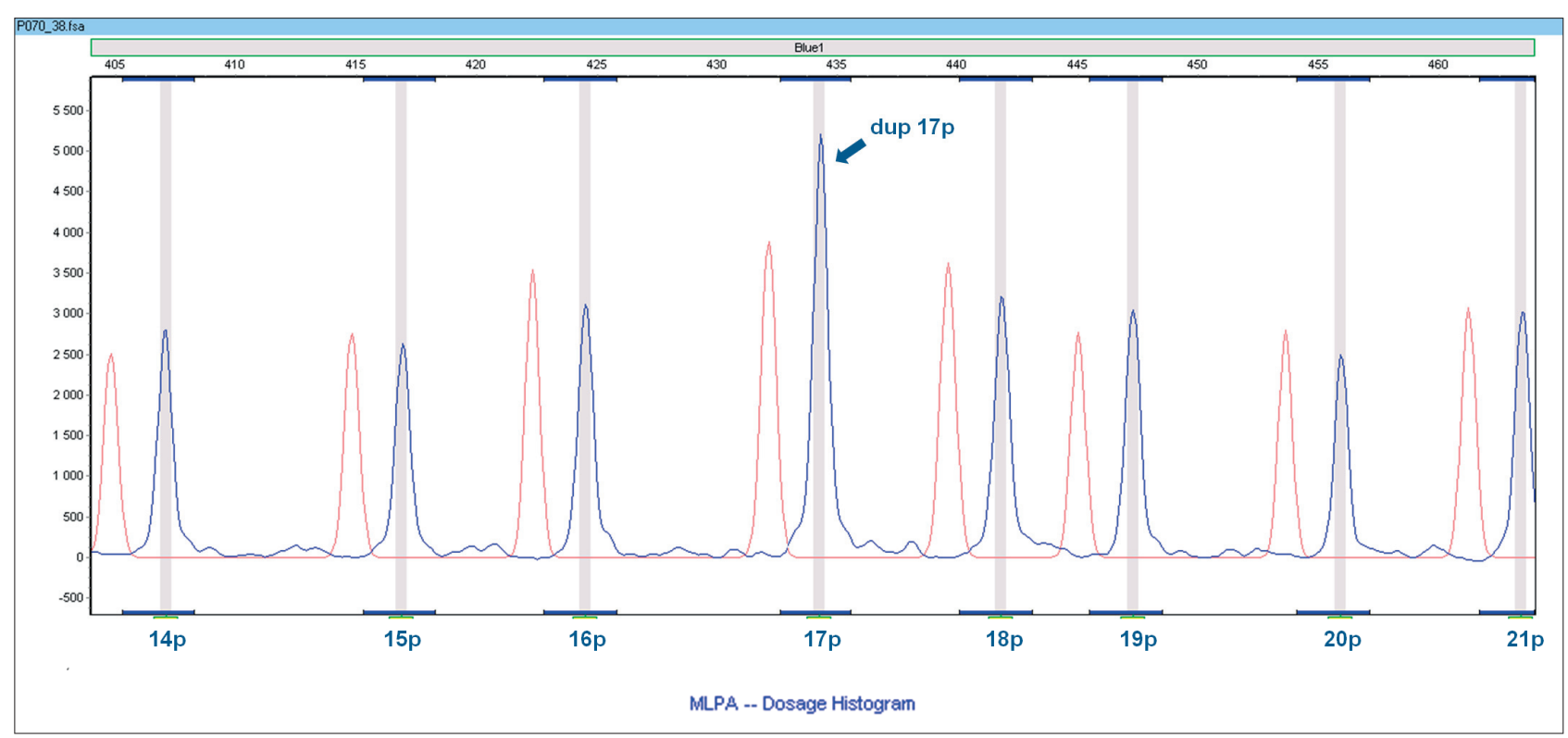

Fig. 1. MLPA analysis presenting a terminal duplication of the short arm of chromosome 17. In our case, the fluorescence signal (peak height) for the 17pter region is increased (blue peak) with respect to the control sample (red peak).

visualization of the choroidal blood vessels, and altered visual evoked potentials (VEP) were noted. This picture, together with other features - hypopigmentation of the skin and hair - for someone could be suggestive with the diagnosis of oculocutaneous albinism type 2 (OCA2) or type 4 (OCA4), which are very similar.

Psychological examination at 6 years assessed her development at the level of a 2 year old. Autism was excluded.

At 1 year 4 months she was referred for genetic counseling because of developmental delay and albinism. Physical examination revealed facial dysmorphy (Fig. 4): impression of hypertelorism, downslanting palpebral fissures with ptosis, slightly broad nasal bridge with bulbous nasal tip, small mouth, and open-mouth appearance.

\section{RESULTS}

Conventional cytogenetic analysis performed on G-banded metaphase chromosomes in the proband showed a normal karyotype. Laboratory tests toward Rett and Angelman syndromes (DNA methylation testing of the SNRPN region) revealed no aberration.

MLPA (multiplex ligation-dependent probe amplification) analysis for subtelomeric regions carried out using commercially available SALSA MLPA P036 and P070 human telomere kits (MRC-Holland, Amsterdam, the Netherlands) revealed the presence of a terminal duplication of the short arm of chromosome 17 (Fig. 1).

FISH (fluorescence in situ hybridization) analysis with a subtelomeric probe for chromosome 17p (Cytocell Ltd., Cambridge, UK) confirmed the duplication (three signals for the $17 \mathrm{p}$ region noted) showing that an extra copy of the 17 pter fragment resided on the non-deleted terminal region of chromosome $14 \mathrm{p}$ (FISH with a wholechromosome painting probe for chromosome 14 was also performed) (Fig. 2). Parental chromosome investigations for the 17pter duplication (karyotyping and FISH) gave normal results, proving the de novo occurrence of this aberration in the patient.

To precisely characterize this chromosomal aberration, a whole-genome oligonucleotide microarray [NimbleGen Human CGH 3x720K Whole-Genome Tiling v3.0 array which contains 720000 oligonucleotide probes (probe length: 60-mer) with a median probe spacing of $2509 \mathrm{bp}$ ] was subsequently performed. It showed the terminal duplication of chromosome 17 with the prox-

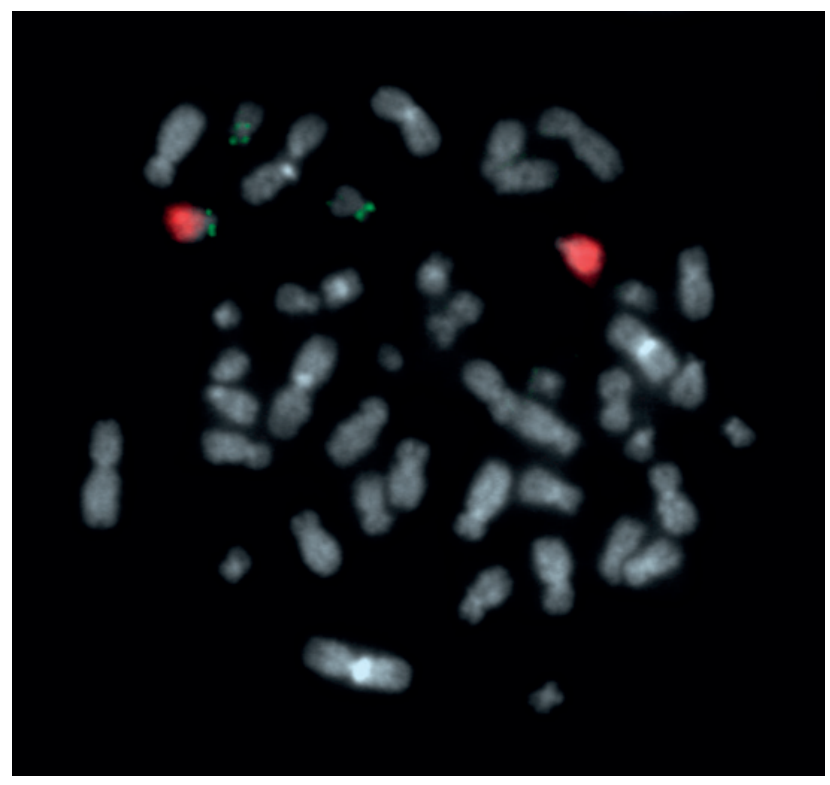

Fig. 2. FISH analysis showing a terminal duplication of the short arm of chromosome 17 confirmed by a probe specific for the subtelomeric region of chromosome $17 \mathrm{p}$ (the triple green signal). The red signal is a whole-chromosome 14 painting probe. 


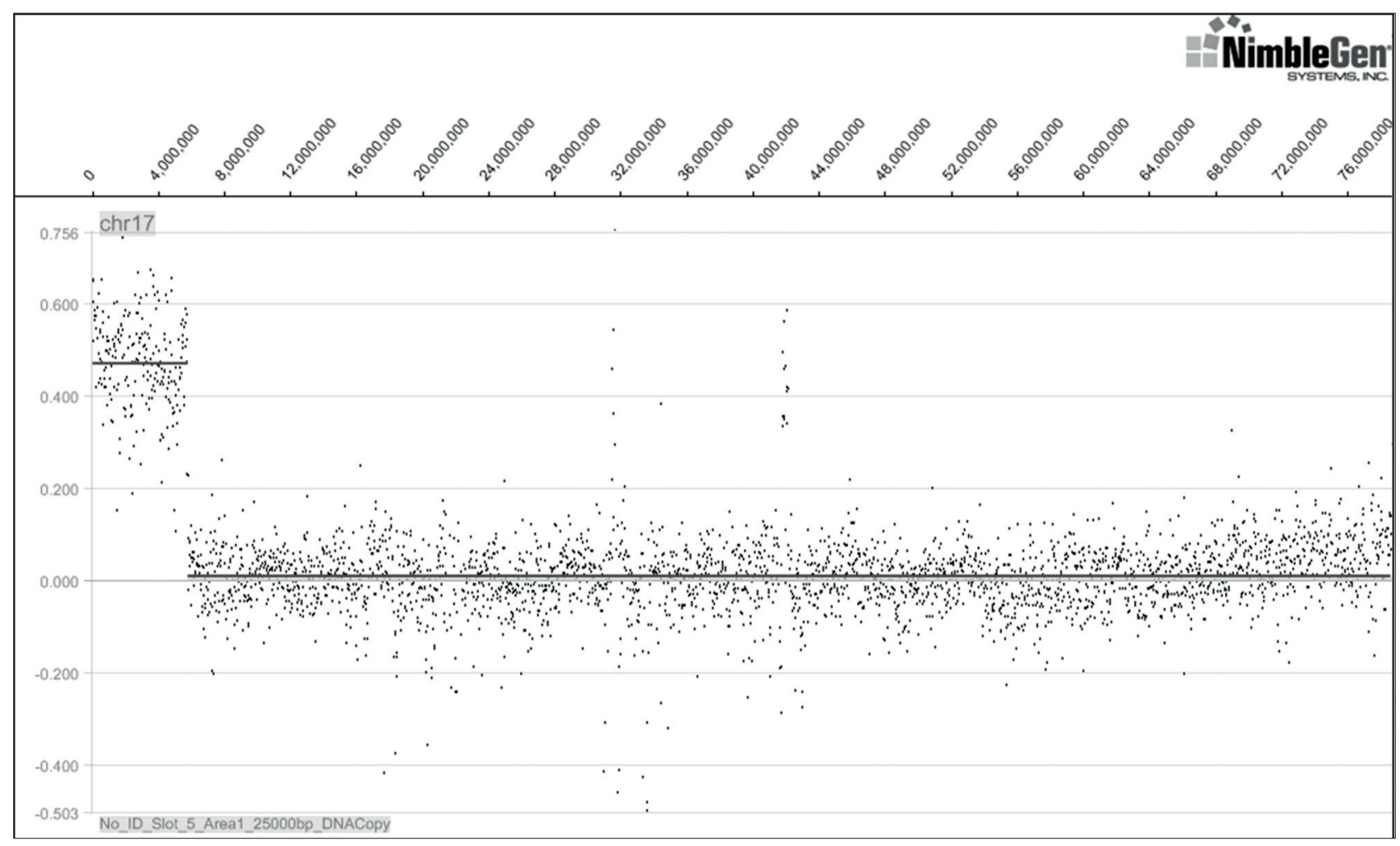

Fig. 3. Array CGH analysis showing a copy number gain (5.77 Mb in size) of chromosome region 17p13.2-pter with the proximal breakpoint at 5,770,000 bp in band p13.2. Data visualization with the use of Roche NimbleGen's SignalMapTM v1.9 software.

imal breakpoint at 5,770,000 bp in band p13.2 (Fig. 3). No other large potentially pathogenic gains or losses in other chromosome regions (in particular deletion of 14pter) were identified except for known copy number variations. The patient's final karyotype was defined as: $46, X X$.arr 17p13.2p13.3(1-5,770,000)x3dn. The size of the duplication is approximately $5.77 \mathrm{Mb}$.

\section{DISCUSSION}

The patient presented herein is the next reported patient with a pure de novo $17 \mathrm{p} 13.3$ duplication. Interestingly, aberrations consisting solely of a unidirectional translocation of a segment of one chromosome (17p in our case) into another chromosome ( $14 \mathrm{p}$ in the presented patient) are rare. Usually, an accompanying deletion occurs and chromosome is duplicated when their sticky ends remain connected to one another. Nonetheless, in our patient, similarly as in the publications of Avela et al. and Kiiski et al., no reciprocal event could be detected ${ }^{6,8}$.

The dysmorphic features observed in our proband are in agreement with the findings in the few probands described to date ${ }^{3,4,8}$. These comprise a marked hypotonic and long face, downslanting palpebral fissures, low-set ears, small nose with round tip and small mouth. The only sign that has not been mentioned in the other patients and is observed in ours is hypopigmentation, albeit in the figures presented by Roos et al., blond hair is noted (especially in Patient 1 at 14 years). Three patients described by Roos et al. had aberrations ranging in size from 1.8 to 4.0 $\mathrm{Mb}$, with a $1.8 \mathrm{Mb}$ region of overlap ${ }^{3}$, which included

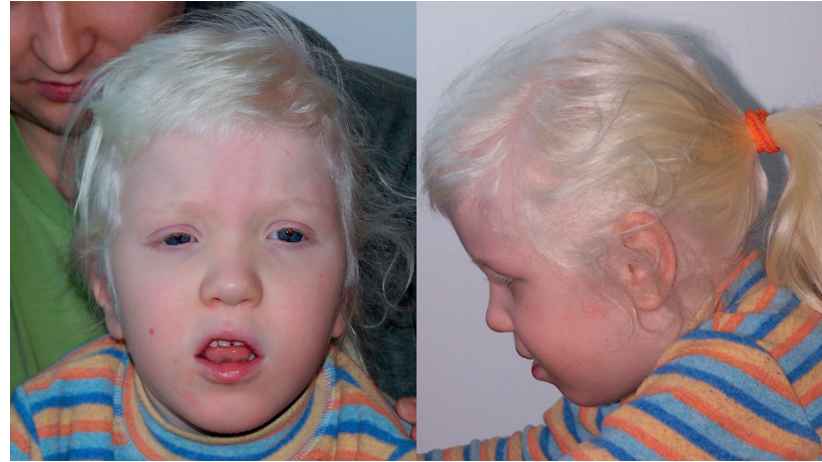

Fig. 4. The phenotype of the presented patient with $17 \mathrm{p} 13.3$ duplication.

the following eight genes from the MDLS critical region: PRPF8, RILP, SCARF1, PITPNA, SKIP, MYOIC, CRK, and $Y W H A E$ (Fig. 5). All had hypotonia, mild to moderate psychomotor delay, and dysmorphic features (the most common: frontal bossing, low-set ears, small nose with broad nasal bridge, hypertelorism and downslanting palpebral fissures, triangularly-shaped chin).

In one patient described in the literature, failure to thrive and poor growth were noted, while another presented overgrowth, with a marfanoid habitus. In a third patient, brain MRI revealed hypoplasia of the corpus callosum and dilated lateral ventricles. Generally, the anthropometric parameters vary among the described patients from a tendency towards tall stature, normal growth, to even growth retardation ${ }^{3,4}$.

To date, duplication of $Y W H A E$ gene is associated with overgrowth or relatively higher body weight and/or length, 


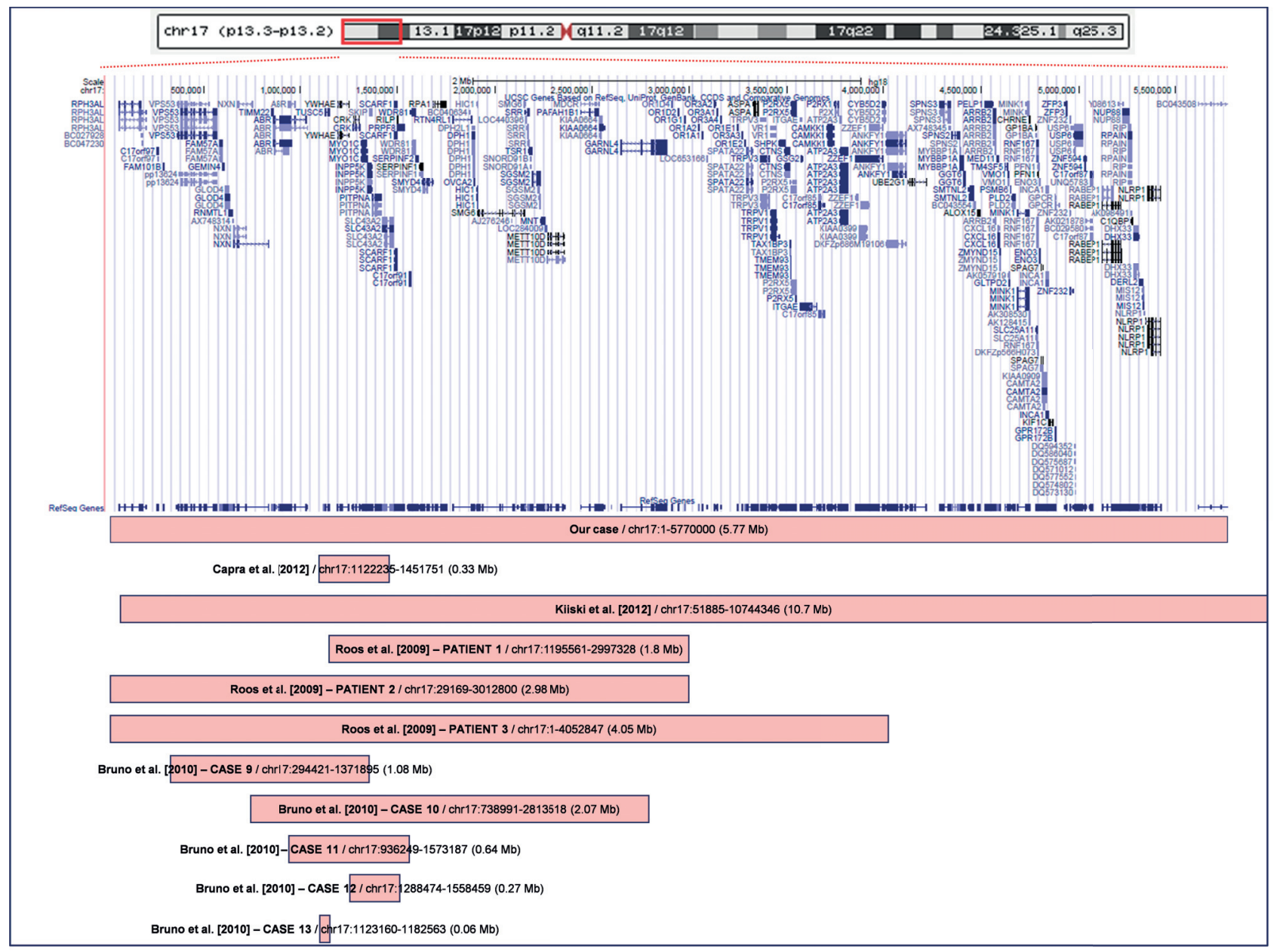

Fig. 5. The extent of the duplicated $17 \mathrm{p} 13$ area in selected patients in relation to the duplicated region in our case and to gene content.

but only if the duplicated region also included the $C R K$ gene which is involved in growth regulation and cell differentiation ${ }^{2}$.

The phenotype observed in $17 \mathrm{p} 13.3$ duplication varies, depending on $Y W H A E$ or PAFAHIBI involvement. This has suggested the need to classify the patients into two groups according to which gene is involved in the chromosomal duplication (Fig. 5) (ref. ${ }^{4}$ ).

Bi et al. concluded that in the individuals with $Y W H A E$ duplication macrosomia, mild neurocognitive and pervasive developmental disorder, as well as subtle dysmorphic craniofacial features were observed, whereas the duplication including $P A F A H 1 B 1$ resulted in a severe total body growth restriction and moderate to severe developmental delay ${ }^{2}$. Moreover, the patients with duplication of PAFAHIBI but not YWHAE or CRK showed relative microcephaly or mild brain structural anomalies ${ }^{2,6}$.

In Table 1 we have summarized the major clinical features of 17 p13 duplication in relation to gene content.

In our proband, apart from features observed in other cases and noted in Table 1, oculocutaneous albinism is present. We have no molecular confirmation of suggested by referring physician oculocutaneous albinism type 2 , hence the occurrence of hypopigmentation in duplication 17 p13 as a feature or coincidence cannot be proved. We were enabled to molecular test for $O C A 2$ gene. However, the patient's father also has blond hair and myopia (we do not know his other ocular findings) what makes the diagnosis of oculocutaneous albinism type 2 in our proband very unlikely. It is a disease of highly variable phenotype but of autosomal recessive inheritance in which, as a rule, parents are asymptomatic. We suppose that this type of albinism was suspected mainly because it is most common forms of albinism in the world and without taking into account the family history.

More than 30 genes are localized in the region duplicated in our patient (17p13.2-pter) (Fig. 5). Unfortunately, specific correlations of individual genes with the clinical symptoms of the patient could not be delineated. None of the analyzed genes within 17p13.2-pter are known to influence pigmentation. Taking into account the fact that patient's father also has blond hair and myopia but no chromosomal aberration, the relationship of albinism with identified duplication is doubtful. Rather, it seems reasonable to suspect monogenic aberration of autosomal dominant inheritance, caused by a point mutation in another gene(s) outside of the duplicated chromosomal region.

In the mouse, for example, more than 150 genes are known to affect pigmentation ${ }^{9,10}$. In humans, the most studied genes resulting in isolated oculocutaneous albinism are TYR (on chromosome 11q14.3), OCA2 (on 
Table 1. Proposed genotype-phenotype correlation in duplication 17p13 (based on Bruno et al.).

\begin{tabular}{ll}
\hline Duplicated gene & Major clinical features \\
\hline YWHAE & autistic manifestations/behavioural problems, \\
psychomotor delay, & hand/foot malformations, \\
& tendency to overgrowth, \\
& craniofacial dysmorphism* \\
& hypotonia, \\
PAFAH1B1 & microcephaly/brain structural abnormalities, \\
(with/without $C R K$ and $Y W H A E)$ & developmental delay, \\
& severe growth restriction, \\
& craniofacial dysmorphism* \\
\hline *Prominent forehead and pointed chin are shared by both the class I and class II duplications
\end{tabular}

chromosome 15q11.2-q12), TYRP1 (on 9p23, structurally similar to TYR), and SLC45A2 (on $5 \mathrm{p} 13.2$ ). In our proband, also OCA other than type 2, as an autosomal recessive disorders, unlikely to be inherited from affected father, i.e. the more common forms: OCA1, OCA3 and OCA4 or more recently described: OCA5 (ref. ${ }^{11}$ ), OCA6 (ref. ${ }^{12}$ ) and OCA7 (ref. ${ }^{13}$ ). It can be expected that with the further advent of next-generation sequencing (whole exome sequencing; WES) we will find more molecular evidence for new genes contributing to the albino phenotype.

In this paper we delineated the molecular syndromology of duplication within 17p12.3-pter, which seems to manifest with a quite specific and recognizable phenotype. Moreover, we hope we have provided new data for further genotype correlation in syndromes with oculocutaneous albinism.

\section{ACKNOWLEDGEMENT}

This study was supported in part by grants from the Polish Ministry of Science and Higher Education (No. 0605/B/P01/2009/37 and No. 0193/IP1/2013/72). Acquisition of the Roche NimbleGen microarray platform was co-financed by ERDF project POIG.02.01.0014-059/09.

Author contributions: MKuc, AJS: literature search, manuscript writing; DGB, MKug, AC: clinical evaluation of the patient and her family; MKuc, MP: molecular analysis and interpretation; AJS: data collection, clinical data interpretation, study design; MKW: final approval.

Conflict of interest statement: The authors state that there are no conflicts of interest regarding the publication of this article.

\section{REFERENCES}

1. Paskulin GA, Zen PR, Rosa RF, Manique RC, Cotter PD. Report of a child with a complete de novo 17p duplication localized to the terminal region of the long arm of chromosome 17. Am J Med Genet A 2007;143A(12):1366-70.
2. Bi W, Sapir T, Shchelochkov OA, Zhang F, Withers MA, Hunter JV, Levy T, Shinder V, Peiffer DA, Gunderson KL, Nezarati MM, Shotts VA, Amato SS, Savage SK, Harris DJ, Day-Salvatore DL, Horner M, Lu XY, Sahoo T, Yanagawa Y, Beaudet AL, Cheung SW, Martinez S, Lupski JR, Reiner O. Increased LIS1 expression affects human and mouse brain development. Nat Genet 2009;41(2):168-77.

3. Roos $L$, Jønch AE, Kjaergaard S, Taudorf K, Simonsen H, HamborgPetersen B, Brøndum-Nielsen K, Kirchhoff M. A new microduplication syndrome encompassing the region of the Miller-Dieker (17p13 deletion) syndrome. J Med Genet 2009;46(10):703-10.

4. Bruno DL, Anderlid BM, Lindstrand A, van Ravenswaaij-Arts C, Ganesamoorthy D, Lundin J, Martin CL, Douglas J, Nowak C, Adam MP, Kooy RF, Van der Aa N, Reyniers E, Vandeweyer G, Stolte-Dijkstra I, Dijkhuizen T, Yeung A, Delatycki M, Borgström B, Thelin L, Cardoso $C$, van Bon B, Pfundt R, de Vries BB, Wallin A, Amor DJ, James PA, Slater HR, Schoumans J. Further molecular and clinical delineation of co-locating 17p13.3 microdeletions and microduplications that show distinctive phenotypes. J Med Genet 2010;47(5):299-311.

5. Capra V, Mirabelli-Badenier M, Stagnaro M, Rossi A, Tassano E, Gimelli S, Gimelli G. Identification of a rare 17p13.3 duplication including the BHLHA9 and YWHAE genes in a family with developmental delay and behavioural problems. BMC Med Genet 2012;13:93.

6. Avela K, Aktan-Collan K, Horelli-Kuitunen N, Knuutila S, Somer M. A microduplication on chromosome 17p13.1p13.3 including the PAFAH1B1 (LIS1) gene. Am J Med Genet A 2011; 155A(4):875-9.

7. Curry CJ, Rosenfeld JA, Grant E, Gripp KW, Anderson C, Aylsworth AS, Saad TB, Chizhikov VV, Dybose G, Fagerberg C, Falco M, Fels C, Fichera M, Graakjaer J, Greco D, Hair J, Hopkins E, Huggins M, Ladda R, Li C, Moeschler J, Nowaczyk MJ, Ozmore JR, Reitano S, Romano C, Roos L, Schnur RE, Sell S, Suwannarat P, Svaneby D, Szybowska M, Tarnopolsky M, Tervo R, Tsai AC, Tucker M, Vallee S, Wheeler FC, Zand DJ, Barkovich AJ, Aradhya S, Shaffer LG, Dobyns WB. The duplication 17 p13.3 phenotype: analysis of 21 families delineates developmental, behavioral and brain abnormalities, and rare variant phenotypes. Am J Med Genet A 2013;161A(8):1833-52.

8. Kiiski K, Roovere T, Zordania R, von Koskull H, Horelli-Kuitunen N. Prenatal diagnosis of 17p13.1p13.3 duplication. Case Rep Med 2012;2012:840538.

9. Yamaguchi Y, Hearing VJ. Physiological factors that regulate skin pigmentation. Biofactors 2009;35(2):193-9.

10. Yamaguchi Y, Hearing VJ. Melanocytes and their diseases. Cold Spring Harb Perspect Med 2014;4(5).

11. Kausar T, Bhatti MA, Ali M, Shaikh RS, Ahmed ZM. OCA5, a novel locus for non-syndromic oculocutaneous albinism, maps to chromosome 4q24. Clin Genet 2013;84(1):91-3.

12. Wei AH, Zang DJ, Zhang Z, Liu XZ, He X, Yang L, Wang Y, Zhou ZY, Zhang MR, Dai LL, Yang XM, Li W. Exome sequencing identifies SLC24A5 as a candidate gene for nonsyndromic oculocutaneous albinism. J Invest Derm 2013;133:1834-40.

13. Gronskov K, Dooley CM, Ostergaard E, Kelsh RN, Hansen L, Levesque MP, Vilhelmsen K, Møllgård K, Stemple DL, Rosenberg T. Mutations in C10orf11, a melanocyte-differentiation gene, cause autosomalrecessive albinism. Am J Hum Genet 2013;92(3):415-21. 